\title{
A right to confidentiality or a duty to disclose? Ethical guidance for conducting prevention research with children and adolescents
}

\author{
Ioana E. Hiriscau • Nicola Stingelin-Giles • \\ Christina Stadler • Klaus Schmeck • \\ Stella Reiter-Theil
}

Received: 22 August 2013/ Accepted: 2 February 2014/Published online: 12 March 2014

(c) Springer-Verlag Berlin Heidelberg 2014

\begin{abstract}
Conducting prevention research with children and adolescents raises ethical challenges especially regarding confidentiality. Research with children and adolescents often applies methodologies which aims at the disclosure of sensitive information about practices that impact on adolescent mental and physical health such as sexual activity, smoking, alcohol consumption, illegal drug use, self-damaging and suicidal behaviour (ideation and attempts). The scope of the article is to review normative documents that cover topics relevant for confidentiality when conducting research with children and adolescents. A systematic literature search in MEDLINE was performed to identify relevant international and European guidelines and codes of ethics that cover health, behavioural and social science research. Additionally, the European Research Ethics website was consulted for double check. However, none of the documents aimed at biomedical, behavioural or social research offers concrete support in resolving practical research ethics problems regarding confidentiality. The codes show a lack of clarity in any circumstances in which the researcher might have an obligation to breach confidentiality by disclosing sensitive information. Only little information is given on what kind of disclosed information, if disclosed, might justify breaching confidentiality. The findings prove a need for normative documents to address the ethical questions regarding confidentiality arising in research practice
\end{abstract}

I. E. Hiriscau $(\bowtie) \cdot$ N. Stingelin-Giles · S. Reiter-Theil

Clinical Ethics, Psychiatric Hospitals of the University Basel, University Hospital Basel, IBMB, Wilhelm Klein-Strasse 27, 4012 Basel, Switzerland

e-mail: e.hiriscau@unibas.ch

C. Stadler $\cdot$ K. Schmeck

Department of Child and Adolescent Psychiatry, Psychiatric

Hospitals of the University Basel, Basel, Switzerland explicitly and specifically. Moreover, further forms of ethical guidance should be developed to support ethical research with children and adolescents.

Keywords Adolescents · Children · Confidentiality · Research ethics · Risk-taking/suicidal behaviour · Sensitive topics

\section{Introduction}

Prevention research involving children ${ }^{1}$ and adolescents raises ethical challenges, especially regarding confidentiality and disclosure; this is of particular interest in the context of physical and mental health research focusing on the prevention of self-damaging and suicidal behaviour. Recent projects such as the European SEYLE Study "Saving and Empowering Young Lives in Europe: promoting health through prevention of risk-taking and selfdestructive behaviours" [1,2] illustrate the need for ethical advice in this realm.

\footnotetext{
${ }_{1}$ Although it is common to define children by reference to age and the level of children's biological and psychological development, definition of children is more complex. According to World Health Organization (WHO), the term "children" is used to cover all age groups from birth to age 19, strict terminology refers to "newborns" (1-28 days), "infants" (up to 12 months), "children" (from 1 up to 10 years), "adolescents" (10-19 years). Other organizations (e.g. UNICEF) may use different age groupings (UNICEF considers children as being up to 18 years old). According to the US federal regulations for research, "children are persons who have not attained the legal age for consent to treatments or procedures involved in the research, under the applicable law of the jurisdiction in which the research will be conducted". Under this definition, not all adolescents who are under the legal age of majority are defined as children.
} 
Children and adolescents differ from adults in their cognitive, emotional and social capabilities as well as their legal status. Besides physiological maturation, children undergo a range of social and emotional changes during adolescence related to their identity formation. Four stages of growth are commonly described: infancy (birth to age 2), early childhood (3-8 years), later childhood (9-12 years) and adolescence (13-18 years). The Convention on the Rights of the Child defines child as "every human being below the age of eighteen years unless the law applicable to the child, majority is attained later" (Article 1) [3]. The term adolescent is used to describe young people who are in the stage of development that occurs between the beginning of puberty until adulthood. Adolescent maturation is related to the personal development where children establish their own beliefs, values, and what they want to accomplish in life. Early adolescence (11-13) is mainly characterized by the development of the adolescent's new self-image due to the physiological changes occurring. The acquiring of new skills of logical thinking and abilities to make rational judgements are associated with these changes. In mid-adolescence (14-15), their cognitive and intellectual capacities increase, they grow emotionally, and their peer group contacts become dominant compared to family background. Characteristic for this period is that the adolescents strive to loosen their ties to the parents, to stabilize their own set of values, to explore new ideas, to shape their educational trajectory and personal outlook. It is during this time that the adolescents gain more autonomy associated with the awareness of an increased sense of responsibility. The late adolescence is mainly focused on the formation of adolescents' identity and their place in society [4]. Adolescence is shaped by specific experiences such as changes in the child-parent relationship, the increasing peers' influence, greater desires for autonomy and independence, involvement in romantic relationships and engagement in risk-taking behaviours [5]. In the last decades, many studies in the risk-behaviour area aimed to identify the underlying mechanisms of the decision that drive young people to engage themselves in "at-risk activities". According to the theories of developmental psychology, the emergence of exploratory and risk-taking behaviours in adolescence is often described as a normal developmental phenomenon marked by the onset of major changes in biological, cognitive, psychological, social, and environmental processes [6, 7]. As supported by the studies, the decision to undertake this kind of activities is determined by the cognitive, affective and social development [8]. Some studies highlighted that adolescents have problems with emotional control; they may react by manifesting transient emotional states regarding problems in situations where normally cognitive mechanisms would be more appropriate. The results from existing studies suggest that moodiness (volatility of mood) is characteristic of adolescents indicating that they have more rapid and more extreme mood swings (both positive and negative) than adults [9]. Moreover, some evidence suggests that thrill seeking and disinhibition are higher during adolescence than in adulthood.

Behavioural problems considered accountable for most of the morbidity and mortality in the adolescent population are substance use and unsafe sexual practices [10]. The research in this area aims to improve the knowledge about the factors influencing adolescent behaviour, to investigate the effectiveness of interventions that may prevent risky behaviours as well as to increase protective behaviours. Many adolescent health problems are related to sensitive, even illicit, behaviours such as underage drinking, illegal drug use, smoking, sexual activity, self-damaging and suicidal behaviour (attempts and ideation). Conducting research on these topics requires that adolescents disclose intimate information about sexual life, habits, secrets as well as disorders. The main concern of the children and adolescents regarding disclosure of information on their personal behaviour to their parents is related to the likelihood that this could produce a crisis in their private environment (family) [11, 12]. To enhance the likelihood that they will honestly disclose information, a promise of confidentiality may be required. However, a promise of full confidentiality might be difficult to be kept. If children and adolescents during the data collection reveal information that suggests they might be at risk to be harmed, researchers may have an ethical and legal duty to disclose this information. In this respect, the most common ethical dilemma of the researcher concerns the decision of whether or not to inform the parents about any risky behaviour identified in the study [13].

The research questions addressed in this paper are the following:

- To what extent should children and adolescents enjoy the right to confidentiality in health prevention research?

- Under which circumstances will breaching confidentiality be justified, or even a duty? Towards whom does any duty to disclose exist?

- How should any breach of confidentiality be handled?

In this paper, we analyse and discuss what recommendations are made in research ethics codes and guidelines regarding confidentiality in studies with children and adolescents. Firstly, we will define the key concepts-privacy, confidentiality and related issues, assent and consent. In "Results", the findings of the analysis of normative documents ${ }^{2}$ identified as relevant for the topic will

\footnotetext{
${ }^{2}$ Given the importance of ethics for the conduct of research, various professional associations have adopted specific codes, guidelines, and policies for their research. Normative documents have a status lying between ethics (theory) and law; thus, they are sometimes called "soft law".
} 
be presented. We will then discuss the shortcomings located in the documents regarding the conduct of research with children and adolescents and formulate some conclusions.

\section{Background and definition of key concepts}

Although confidentiality is commonly viewed as being akin to the principle of privacy, the two terms should be differentiated $[14,15]$. Privacy can be defined as "the right of the individual to be protected against intrusion into his personal life or affairs, or those of his family, by direct physical means or by publication of information" [16]. Privacy refers to persons and to their interest in controlling the access of others to themselves. Confidentiality refers to the treatment of information, samples or data that an individual has disclosed in a relationship of trust and with the expectation that it will not be divulged to others in ways that are inconsistent with the understanding of the original disclosure, without permission being given [17, 18]. The information supplied during an informed assent and consent process must include stating if and how confidentiality of information and data will be secured and assured. However, it is arguably also necessary that potential research participants be informed of the circumstances under which confidentiality might be breached [19]. When the research involves collection of personal information (e.g. history of abuse, drug use) or some health-related data, the investigator must consider the risks related to possible breach of confidentiality, and decide how to cover such risks in the information supplied to ensure that consent and assent are informed [20-22]. Confidentiality in the area of children and adolescents' risky behaviour is particularly sensitive regarding their stage of personality development and when considering the interwoven risks of harm to which children and adolescents are often exposed, e.g. sexually transmitted diseases or the abuse of various substances that are readily available and that may be promulgated by peer pressure $[23,24]$. Noting that risk is a complex and contested term, it refers in this paper to the physical, psychological and social harms that can arise from research aimed at generating preventive knowledge on mental and physical health [25].

Researchers conducting studies with children and adolescents are challenged to carefully balance the need for their participation in the research and the need to protect them as well as not infringing their rights $[26,27]$. One of the most basic ethical and legal requirements in conducting research is the obligation to obtain informed consent of participants [28]. Legally, the minor can just give assent, the age of 18 being considered the limit for a valid consent with few exceptions ${ }^{3}$ [29]. The term «assent» is usually applied when referring to children and adolescents who are not deemed to be competent. Assent carries less weight than informed consent, but provides the alternative of an affirmative agreement of a child for participating in the research [30]. The research context may influence the investigator's considerations about confidentiality, the autonomy of the participants by compromising the validity of their own consent or assent $[31,32]$. This might happen when they agree to participating in the research under the pressure of parents or influence of their peer group. When the research takes place in school settings, children and adolescents may accept to participate just because they feel that activities in schools are compulsory or because they do not want to upset their teachers.

\section{Method}

A systematic literature search was performed in MEDLINE and the European Research Ethics (ERE) ${ }^{4}$ website of European Union (EU) to identify normative documents such as ethics codes and guidelines at the international or European level covering a range of topics relevant to the context of prevention research involving children and adolescents. One author performed the literature search for ethical codes and guidelines. Two of the authors independently reviewed all resulting citations and checked them for identifying the references relevant to confidentiality in research with children and adolescents. Disagreements regarding the eligibility of articles were resolved by consensus building after reading the full text. We used the search driver only in English. MEDLINE was searched for all years using the following search algorithm, following the CONSORT Statement requirements ${ }^{5}$ (see Fig. 1): "Guideline" (publication type) AND Topic $=$ research

\footnotetext{
${ }^{3}$ In the USA, the state laws have recognized the right of minors with a certain status, such as "mature" or "emancipated" minors (including those who are married or in military service) to consent to their own care. Other minors authorized to consent may include those who are parents or are living independently of their own parents. The definition of "children" in the federal regulations (which includes adolescents who are minors) specifically references state laws on treatment for health care and the age at which an individual can independently consent under these laws to specific treatment or care. Relevant state laws include those addressing age of majority, emancipation status, age to consent for general medical care, and care of minors for specific conditions such as sexually transmitted diseases (STD) and substance use; few states have laws addressing participation of adolescents in research.

4 The aim of the website is to give researchers access to and information on the guidelines, ethics codes and laws, at European and international level that regulate the research process http://www. ethicsweb.eu.

5 http://www.consort-statement.org/.
} 
Fig. 1 Selection of the publications

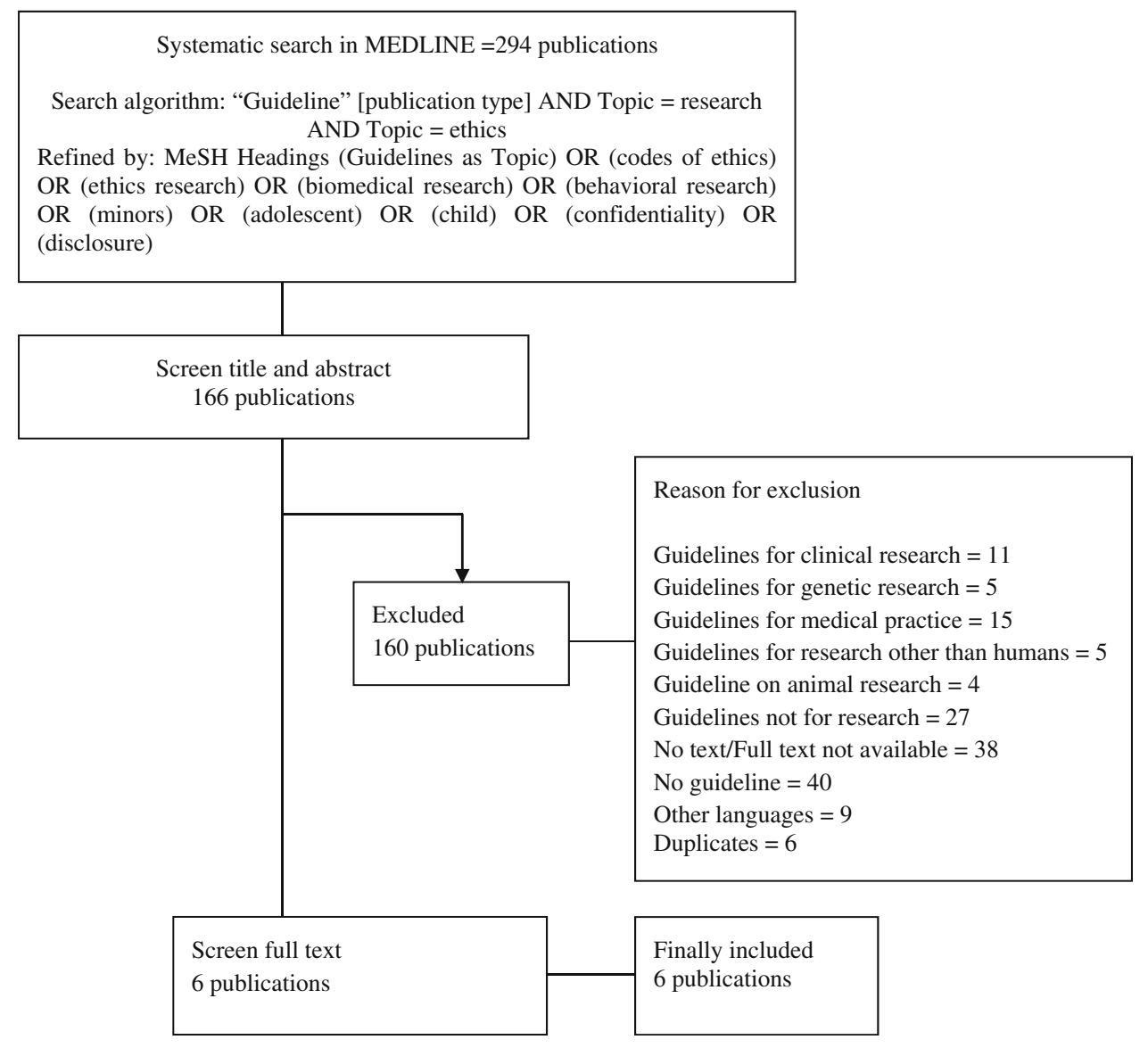

AND Topic $=$ ethics, Refined by: MeSH Headings (Guideline as Topic) OR (code of ethics) OR (ethics research) OR (biomedical research) OR (behavioural research) OR (minors) OR (adolescent) OR (child) OR (confidentiality) OR (disclosure).

Finally included publications:

- The Nuremberg Code (1947),

- Additional protocol to the Convention on Human Rights and Biomedicine, concerning Biomedical Research (2005),

- Guidelines for the ethical conduct of medical research involving children. British Paediatric Association (2000),

- International Ethical Guidelines for biomedical research involving human subjects. Council for International Organizations of Medical Sciences (CIOMS 2002),

- Guidelines for informed consent in biomedical research involving paediatric populations as research participants. Ethics Working Group of Confederation of European Specialists in Paediatrics (CESP 2002),

- Guidelines for adolescent health research. A position paper of the Society of Adolescent Medicine (2003).
The EU website ERE was consulted for double check. Besides the six final included publications, additional documents were selected based on the following inclusion and exclusion criteria:

- Document is an ethics code or a guideline which covers medical, behavioural and social science research, excluding genetic and clinical trials regulations;

- Document represents a text of principles or guidance for researchers dealing with ethical issues;

- Document has been developed by government agencies, organizations of governing boards or expert panels.

According to the criteria mentioned above, the following five normative documents were searched for relevance and full text screened:

- The Declaration of Helsinki (Ethical Principles for Medical Research Involving Human Subjects 1964),

- The Belmont Report (Ethical Principles and Guidelines for Research Involving Human Subjects 1979),

- Ethical Guidelines for International Comparative Social Science Research (ICSSR) in the framework of MOST (2003), 
- Code of Ethics for Socio-Economic Research RESPECT (2004),

- Code of Federal Regulation, Part 46 Protection of Human Subjects, Subpart D Additional Protection for Children as Subjects in Research (Revised 2009).

\section{Results}

The analysis of the normative documents (a-k) showed the following results:

(a) The Nuremberg Code [33] does not address any information about research involving children and adolescents or confidentiality.

(b) In paragraph 11 of Declaration of Helsinki [34], it is postulated that the protection of privacy and confidentiality of personal information of the research subjects rest on the responsibility of the physician who participates in medical research. Protecting privacy and confidentiality is an ethical imperative which requires special precautions (paragraph 24). The Declaration of Helsinki refers to competent or not competent individuals (Paragraph 27) and does not precisely address children.

(c) The Belmont Report [25] draws attention to "persons with diminished autonomy who are entitled to protection", including children. No other specifications regarding confidentiality in general or related to children or adolescents are given.

(d) In the Additional protocol to the Convention on Human Rights and Biomedicine, concerning Biomedical Research [35] is asserted that the potential research participant should be informed about the procedures required to protect privacy and confidentiality of personal data. This statement is further detailed in chapter VIII, article 25 , regarding the confidential management of personal information collected during biomedical research, but it does not address children and adolescents.

(e) The guidelines for the ethical conduct of medical research involving children issued by British Paediatric Association [36] stated the researchers' duty "to respect confidentiality, and keep up to date with data protection and legislation on access to health records". No further information regarding confidentiality is available.

(f) The Guidelines for informed consent in biomedical research involving paediatric populations as research participants issued by Ethics Working Group of Confederation of European Specialists in Paediatrics (CESP) [28] address some general recommendations for protecting confidentiality of the child participant.
These refer to all personal and health-related information of the child participant collected during the course or in connection to the research. The confidentiality assurance in the data collection and storage of information as well as in any discussion or publication of the research rests on the responsibility of the researcher or paediatrician. The document also stipulates that the consent process must promote and protect the confidentiality of the child and his or her family as well as confidentiality of the child within the family.

(g) CIOMS [37] provides a distinct section regarding research involving children. Guideline 14 refers explicitly to the category of 'emancipated' and 'mature' minors who are below the general age of consent, but they can grant consent for participating in a study without the agreement of their parents or guardian. The parental consent might be waived in research addressing topics such as sexual behaviour, domestic violence or use of recreational drugs when obtaining their agreement may result in a great distress for the minor (see Guideline 14). Yet, related to this issue, no provisions regarding the management of confidentiality are offered. Guideline 18 refers mainly to the limits of the investigator's responsibility to ensure keeping the subjects' data confidential, but it does not address confidentiality in research with children and adolescents. The guideline states that every precaution should be taken to respect the privacy of the subject, the confidentiality of the patient's information and to minimize the impact of the study on the subject's physical and mental integrity. The researcher must establish secure safeguards of the confidentiality of subjects' research data. Prospective subjects should be informed of limits to ensure confidentiality and of the foreseeable adverse social consequences of breaches of confidentiality.

(h) The SAM Guidelines for adolescent health research [23] address the recommendations contained in federal law regarding the protection of confidentiality for adolescent research participants and the conduct of research on socially sensitive subjects, such as illicit drug use, violence, and sexuality. The researchers must comply with HIPAA Privacy Rule [38] which provides confidentiality protection for the health care information of adolescents. According to this Rule, adolescents who are minors as individuals can exercise their rights if they are allowed, by state or other law, to consent for their own care. With respect to disclosure of information to parents and parents' access to protected records, the HIPAA Privacy Rule defers to the provisions of state and 
other law. If state or other law is silent, the Rule defers to the discretion of health care professionals to determine whether information should be accessible to parents.

(i) Ethical Guidelines for International Comparative Social Science Research (ICSSR) in the framework of MOST [39] recommends in paragraph 10 maintaining full confidentiality of all information and the anonymity of participants, emphasizing the need to put in place procedures for safeguarding confidentiality. Participants should be informed of any potential limitations to confidentiality. The recommendations are not specified for children and adolescents.

(j) In the Code of Ethics for Socio-Economic Research RESPECT [40], the assurance of confidentiality and anonymity in research of sensitive matters such as drug use and sexual behaviour is emphasized. The code recommends also the necessity to review and assess continuously issues of confidentiality and anonymity throughout the research. Here are stated explicitly the situations covered by law requirement in which confidentiality has to be breached, referring to child abuse or participants harming themselves or others. Special attention is to consider regarding management of confidentiality when investigating violent or deviant behaviour (drug abuse, assault, burglary) but no recommendations regarding children and adolescents are offered.

(k) The Code of Federal Regulation (CFR), Part 46 Protection of Human Subjects, Subpart D Additional Protection for Children as Subjects in Research applies to all types of research involving children [41]. In the CFR general provisions is stated that the confidentiality of the personally identifiable information must be maintained throughout the research and thereafter. When appropriate, there are adequate provisions to protect the privacy of subjects and to maintain the confidentiality of data.

\section{Discussion}

The codes reveal a lack of specification regarding children and adolescents and confidentiality in research in general, with no attention being given to confidentiality of sensitive data. Only few, general recommendations regarding confidentiality in sensitive research are provided by some codes $[23,38]$. In the documents, the terminology used to describe minor participants does not differentiate between children and adolescents, i.e. those under the legal age, who are deemed to be competent to grant consent. The content of the codes and guidelines does not deal with personally sensitive or critical data relevant for the physical and mental health of the participants. They also show a lack of clarity in any circumstances in which the researcher might have an obligation to breach confidentiality by disclosing sensitive information. No criteria are provided that allow for the assessment of the type or degree of risk of harm that must be involved to justify or require the breaching of the promise to hold information confidential. No helpful guidance is offered regarding to whom disclosures should be made: to one parent or to both; to social services, the school or to others. Equally, no suggestions are given towards which parties' confidentiality should be maintained if some breach is felt necessary. The documents do not mention or recommend how the consequences for the child or adolescent or the family of breaching confidentiality should be dealt with. Potential limitations of confidentiality should be communicated to participants, but advice is missing on who should be informed.

The researcher's practical dilemma of whether or not to inform the parents or other competent authorities if information is divulged about risky behaviour has to be discussed in the light of principle to avoid harm which is prima facie very strong. The principle of nonmaleficence should be mediated in its application by the principle of showing respect for the child's developing autonomy which acknowledges his/her decision-making right and enables him/her to act autonomously [42]. Researchers should not derive from "prevent harm" a 'carte blanche' justification to disclose all information; the risks of harm must be of a type, quality or quantity that justifies breaking confidentiality [43].

Although protecting the confidentiality of research data is a clear ethical imperative, keeping all information provided confidential might seriously hamper helping those who are in need. Circumstances under which it may be permitted or required to disclose confidential information include situations where a legal obligation exists to do so or where there is an immediate risk of harm that can only be averted or prevented by disclosing information [44, 45]. In this regard, the UK position is clear: "Where a child or young person divulges that they or others are at risk of significant harm, or where the researcher observes or receives evidence of incidents likely to cause serious harm, the researcher has a duty to take steps to protect the child or other children" [46]. Disclosure about illegal behaviour, trauma or abuse raises questions regarding the treatment of this information and concerns about protection of study participants. From a legal standpoint, the participants could be at risk for possible legal action or civil liability by revealing sensitive data (e.g. use of illegal substances), if the researcher's data are later subpoenaed and the subject can be identified [47]. Thus, it is essential that researchers pay attention to protection of the adolescents' anonymity 
and confidentiality and handle the disclosure of obtained sensitive information with respect to and in a manner that enhances trust.

\section{Conclusions}

The analysis of normative documents generates a number of new questions about confidentiality in research with children and adolescents. While suggesting a revision of current ethical codes and guidelines is beyond the range of this article, it is concluded that additional recommendations or amendments complementing the existing codes and guidelines seem necessary. Also, other forms of ethical guidance dedicated to solve practical ethical problems of research with children and adolescents should be considered. Ethical recommendations should be mindful of the possible consequences of breaching a promise to hold information and data confidential, and to measure and take into account the degree of a child's and adolescent's maturity and the extent to which he or she could be held as being autonomous.

\section{Summary points}

- Prevention research with children and adolescents raises major challenges how to manage confidentiality regarding sensitive information.

- If the confidentiality issue is not handled in an appropriate manner, the participation of children and adolescents as well as the ethical justification of the respective study may be questionable.

- The analysis shows that the identified normative documents fail to offer specific help regarding the management of confidentiality, especially on sensitive topics provided by a minor participant and the circumstances justifying a breach of it.

- The development of additional recommendations or amendments to the existing codes and guidelines is suggested. Also, further forms of ethical guidance should be considered for a problem solution as a kind of "ethics support".

Acknowledgments This work has been generously supported by a grant from the BOTNAR Foundation within a Postdoctoral Scholarship Research Ethics under the auspices of the Medical Faculty of Basel University, especially Prof. A. Urwyler (previous Dean) and Prof. Ch. Beglinger (present Dean). The Psychiatric Hospitals of the University Basel hosted the international workshop "(When) Theory meets Practice-Ethical Issues in Research with Minors and other Vulnerable Groups", 14.2.2012, discussing content matters of this article. The contribution of Nicola Stingelin benefited from her work for the ADAMS project, HEALTH-F4-2009-242257, FP7 EU Project.
We are grateful for the valuable contributions from the SEYLE Consortium members within the workshop and project.

Conflict of interest On behalf of all authors, the corresponding author states that there are no conflicts of interest, financial or otherwise.

\section{References}

1. Wasserman D, Carli V, Wasserman C, Apter A, Balazs J, Bobes $\mathrm{J}$, Bracale R, Brunner R, Bursztein-Lipsicas C, Corcoran P, Cosman D, Durkee T, Feldman D, Gadoros J, Guillemin F, Haring C, Kahn JP, Kaess M, Keely H, Dragan M, Nemes B, Postuvan V, Reiter-Theil S, Resch F, Saiz P, Sarchiapone M, Sisask M, Varnik A, Hoven CW (2010) Saving and Empowering Young Lives in Europe (SEYLE): a randomized controlled trial. BMC Public Health 10:192. doi:10.1186/1471-2458-10-192

2. Carli V, Hadlaczky G, Wasserman C, Stingelin-Giles N, ReiterTheil S, Wasserman D (2011) Maintaining confidentiality in prospective studies: anonymous repeated measurements via email (ARME) procedure. J Med Ethics 38:127-129. doi:10.1136/jme. 2011.044552

3. Convention of the Rights of the Child (1989). http://www.ohchr. org/en/professionalinterest/pages/crc.aspx. Accessed 14 Jan 2014

4. Hazen E, Schlozman S, Beresin E (2008) Adolescent psychological development: a review. Pediatr Rev 29:161-167

5. Smetana JG, Campione-Barr N, Metzger A (2006) Adolescent development in interpersonal and societal contexts. Annu Rev Psychol 57:255-284

6. Fischoff B (1992) Risk taking: a developmental perspective. In: Yates JF (ed) Risk-taking behavior. Wiley, Chichester, pp 133-162

7. Steinberg L (2004) Risk-taking in adolescence: what changes, and why? Ann NY Acad Sci 1021:51-58

8. Steinberg L (2005) Cognitive and affective development in adolescence. Trends Cogn Sci 9:69-74

9. Larson R, Csikszentmihalyi M, Graef R (1980) Mood variability and the psychosocial adjustment of adolescents. J Youth Adolesc 9(6):469-490

10. Viner R, Booy R (2005) ABC of adolescence: epidemiology of health and illness. Br Med J 330:411-414

11. Berlan ED, Bravender T (2009) Confidentiality, consent, and caring for adolescent patient. Curr Opin Pediatr 21(4):450-456

12. Sanci LA, Sawer SM, Kang MS, Haller DM, Patton GC (2005) Confidential health care for adolescents: reconciling clinical evidence with family values. Med J Aust 183(8):410-414

13. Mitchell CW, Disque JG, Robertson P (2002) When parents want to know: responding to parental demands for confidential information. Prof Sch Couns 6:156-161

14. Office for Civil Rights (2009) Do you know the difference between "Privacy" and "Confidentiality"? https://www.google. com/url?q=http://research.uthscsa.edu/ocr/Privacy\%2520and\% 2520Confidentiality\%2520in\%2520Human\%2520Research.pdf. Accessed 19 July 2013

15. Report of the Committee on Privacy and Related Matters, Chairman David Calcutt QC (1990) Cmnd. 1102, London: HMSO

16. Beauchamp TL, Childress JF (1994) Principles of biomedical ethics, 4th edn. Oxford University, New York and Oxford

17. Thompson IE (1979) The nature of confidentiality. J Med Ethics 5:57-64. doi:10.1136/jme.5.2.57

18. Boruch RF, Cecil JS (1979) Assuring the confidentiality of social research data. University of Pennsylvania Press, Philadelphia 
19. Powell MA, Fitzgerald RM, Taylor N, Graham A (2012) International literature review: ethical issues in undertaking research with children and young people, for the childwatch International Research Network, Southern Cross University, Centre for Children and Young People, Lismore NSW and University of Otago, Centre for Research on Children and Families, Dunedin, NZ

20. Larcher V (2005) ABC of Adolescence. Consent, competence and confidentiality. Br Med J 330(7487):353-356

21. Rae WA, Sullivan JR, Razo NP, George CA, Ramirez E (2002) Adolescent health risk behavior. When do pediatric psychologists break confidentiality? J Pediatr Psychol 27(6):541-549

22. Stingelin-Giles N (2011) The place of informed consent and community assent in international public health interventions. Dissertation, University of Basel

23. Society for adolescent medicine (2004) Confidential health care for adolescents: position paper of the society for adolescent medicine. J Adolesc Health 35:160-167

24. Lothen-Kline C, Howard DE, Hamburger EK, Worrell KD, Boekeloo BO (2003) Truth and consequences: ethics, confidentiality, and disclosure in adolescent longitudinal prevention research. J Adolesc Health 33(5):385-394

25. Belmont Report (1979) Ethical principles and guidelines for the protection of human subjects of research. The National Commission for the Protection of Human Subjects of Biomedical and Behavioral Research. http://www.hhs.gov/ohrp/humansubjects/ guidance/belmont.html. Accessed 19 Aug 2013

26. Greig A, Taylor J, Mackay T (2007) Doing research with children. Sage Publications, London

27. Peart N, Foley M, Henaghan M (2003) Children as research participants. In: Dawson J, Paert N (eds) The law of research. A guide. Dunedin, University of Otago Press, pp 269-284

28. Gill D (2003) Ethics Working Group of the Confederation of European Specialist in Paediatrics: crawley FP (Belgium), LoGiudice M (Italy), Grosek S (Slovenia), Kurz R (Austria), De Lourdes Levy M (Portugal), Mjones S (Sweden), Nicolopoulos D (Greece), Rubino A (Italy), Sauer PJJ (Netherlands), Siimes M (Finland), Weinding M (UK), Zach M (Austria), Chambers TL (UK). Guidelines for informed consent in biomedical research involving paediatric populations as research participants. Eur J Pediatr 162:455-458

29. De Lourdes Levy M, Larcher V, Kurz R (2003) Informed consent/assent in children. Statement of the ethics working group of the confederation of European specialists in paediatrics (CESP). Eur J Pediatr 162(9):629-633

30. Kon AA (2006) Assent in pediatric research. Pediatrics 117: 1806-1810. http://pediatrics.aappublications.org/content/117/ 5/1806.full.html. Accessed 20 Aug 2013

31. Gans JE, Brindis CD (1995) Choice of research setting in understanding adolescent health problems. J Adolesc Health 17:306-313

32. Koch HG, Reiter-Theil S, Helmchen H (eds) (1996) Informed consent in psychiatry. European perspectives of ethics, law and clinical practice. Nomos, Baden-Baden
33. The Nuremberg Code (1998). In: Tröhler U, Reiter-Theil S (eds) (in collaboration with $\mathrm{E}$ Herych) Ethics codes in medicine. Foundations and achievements of codification since 1947, Ashgate, Aldershot, pp 353-354

34. WMA Declaration of Helsinki: Ethical Principles for Medical Research Involving Human Subjects (1964). http://www.wma. net/en/30publications/10policies/b3/index.html. Accessed 19 Aug 2013

35. Additional protocol to the Convention on Human Rights and Biomedicine, concerning Biomedical Research (Strassbourg) (2005). http://conventions.coe.int/Treaty/en/Treaties/Html/164. htm. Accessed 20 Aug 2013

36. Royal College of Paediatrics and Child Health: Ethics Advisory Committee (2000) Guidelines for the ethical conduct of medical research involving children. Arch Dis Child 82:177-182

37. International ethical guidelines for biomedical research involving human subjects, prepared by the Council of International Organizations of Medical Sciences (CIOMS) in collaboration with the World Health Organization (WHO) Geneva (2002). http://www. cioms.ch/publications/layout_guide2002.pdf. Accessed 19 Aug 2013

38. Department of Health and Human Services (2002) 45 CFR Part 160 and 164. Standards for privacy of individually identifiable health information. http://www.hhs.gov/ocr/privacy/hipaa/admin istrative/privacyrule/. Accessed 15 Jan 2014

39. Ethical Guidelines for International Comparative Social Science Research (ICSSR) in the framework of MOST (2003). http:// www.unesco.org/most/ethical.htm. Accessed 20 Aug 2013

40. EU Code of Ethics for Socio-Economic Research-RESPECT project (2004). http://www.respectproject.org/ethics/412ethics. pdf. Accessed 20 Aug 2013

41. US National Commission for the Protection of Human Subjects of Biomedical and Behavioral Research (1974) Research involving children. http://www.hhs.gov/ohrp/archive/natio nalcommission.html. Accessed 20 Aug 2013

42. Morrow V, Richards MPM (1996) The ethics of social research with children: an overview. Child Soc 10:90-105

43. Ford CA, English A (2002) Limiting confidentiality of adolescent health services. What are the risk? JAMA 288(6):752-753

44. Kemper A, Kölch M, Fangerau H, Fegert JM (2010) Ärztliche Schweigephlicht bei Kindeswohlgefärdung. Mehr Handlungssicherheit durch die neuen Kinderschutzgesetze? Ethik in der Medizin 22(1):33-47

45. Kobocow B, McGuire JM, Blau BI (1983) The influence of confidentiality conditions on self-disclosure of early adolescents. Prof Psychol Res Pract 14(4):435-443

46. Shaw C, Brady L-M, Davey C (2011) Guideline for research with children and young people. National Children's Bureau Research Centre, London

47. Stiles GP, Petrila J (2011) Research and confidentiality: legal issues and risk management strategies. Psychol Public Policy Law 17(3):333-356 